\title{
BMJ Open First use of Simulation in Therapeutic Patient Education (S-TPE) in adults with diabetes: a pilot study
}

Christelle Pennecot (D) , ${ }^{1}$ Maxime Luu (D) , ${ }^{2}$ Claire Marchand, ${ }^{3}$ Rémi Gagnayre, ${ }^{3}$ Nathalie Dechannes, ${ }^{4}$ Sabine Rudoni, ${ }^{4}$ Anne-Marie Hilaire, ${ }^{4}$ Aurore Demongeot, ${ }^{4}$ Delphine Capelle, ${ }^{5}$ Marc Bardou (i) ${ }^{2,6}$

To cite: Pennecot C, Luu M, Marchand C, et al. First use of Simulation in Therapeutic Patient Education (S-TPE) in adults with diabetes: a pilot study. BMJ Open 2022;12:e049454. doi:10.1136/ bmjopen-2021-049454

- Prepublication history and additional supplemental material for this paper are available online. To view these files, please visit the journal online (http://dx.doi.org/10.1136/ bmjopen-2021-049454).

Received 07 February 2021 Accepted 03 February 2022

Check for updates

(c) Author(s) (or their employer(s)) 2022. Re-use permitted under CC BY-NC. No commercial re-use. See rights and permissions. Published by BMJ.

For numbered affiliations see end of article.

Correspondence to Mrs Christelle Pennecot; christelle.pennecot@chu-dijon.fr

\section{ABSTRACT}

Objective To pilot test the feasibility and acceptability of Simulation in Therapeutic Patient Education (S-TPE), in both adult patients with diabetes and educators.

Conception Adult patients with insulin-dependent diabetes and who participated in a full TPE programme for the implementation of a FreeStyle were included in this monocentric pilot study. S-TPE intervention was based on a consensus conference determining the conditions and objectives of S-TPE. Main outcomes were the patients' and educators' perception of the usefulness of S-TPE and the patient's satisfaction level at the conclusion of the simulation sequence, measured on validated scales. Secondary outcomes were organisational, human, material and temporal, facilitating and limiting factors for patients and educators, patient self-efficacy and anxiety scores. Interventions The final session of TPE used the simulation. For each group, one patient volunteered to be the simulated patient. Intervention was divided into three steps: (1) a pre-briefing, (2) a simulation of hypoglycaemia and (3) a debriefing with the group of patients and educators. The whole intervention lasted about 2 hours. Results We included 23 patients (mean age \pm SD $63 \pm 15$ years, 14 men) and 3 educators. After S-TPE intervention, patients' and educators' perceived usefulness score were $20.6 / 25$ and $37.5 / 40$, respectively. Patient's satisfaction score was 51.9/60. Qualitative analysis revealed no limiting factors to implementing S-TPE. Self-efficacy was stable. Decrease in anxiety score after S-TPE reached statistical significance in women (from $35.1 \pm 4.5$ to $32.7 \pm 5.5, p=0.04$ ) but not in men.

Conclusion No limiting factors that could prevent the conduct of clinical trials to assess S-TPE efficacy in patients with diabetes were identified. S-TPE appears as a promising technique to improve diabetes management. Trial registration number Registration $\mathrm{N}^{\circ}$ : 2019-A00773-54 and NTC: 03956927.

\section{INTRODUCTION}

Therapeutic patient education (TPE) administered in a hospital or community context helps chronically ill patients to develop selfcare and daily life skills within the constraints imposed by the disease. ${ }^{12}$ TPE has met the needs of patients with diabetes, ${ }^{3}$ asthma ${ }^{4}$ and heart failure. ${ }^{5}$ Patient benefits include greater

\section{Strengths and limitations of this study}

- This pilot trial is the first to study the feasibility and acceptability of Simulation in Therapeutic Patient Education (S-TPE) in both patients and their helpers.

- S-TPE method used in this study is a standardised intervention based on the recommendations of an expert consensus conference.

- Evaluation was not limited to self-efficacy outcomes but also assessed patients' satisfaction.

- The absence of a control group did not permit to study preliminary efficacy outcomes.

- The limited number of patients did not provide enough power to quantify the benefit of S-TPE on self-efficacy.

compliance, fewer complications, higher quality of life and an increase in perceived health status. ${ }^{6}$ TPE reduces hospital stays and costs, ${ }^{78}$ but there are not enough trained educators, especially in remote areas. ${ }^{9}$ Most TPE programmes only offer instruction but neglect skills necessary for everyday life. ${ }^{10-12}$ Some self-care skills may be difficult to acquire during TPE, including managing uncontrolled and severe hypoglycaemia. ${ }^{13}$

The current evaluation of TPE's contribution to healthcare in patients with diabetes may be too narrow and inadequately captures its effects. In a systematic review of TPE for type 1 diabetes, Fonte $e t a l^{10}$ concluded that studies are too focused on clinical, biological and economic outcomes and often failed to measure psychosocial or coping skills, for which patients must acquire social and practical skills to cope with chronic illness. Unfortunately, no validated teaching method both instructs patients in the necessary skill set and ensures that they can use those skills in daily life.

If TPE training was combined with simulation, patients might find it easier to develop real world coping skills. Simulation provides 
a structured learning environment in which patients can learn to handle real word situations and develop their skills and abilities without imposing ethical, economic or technical risks. ${ }^{14}$ Simulation improves self-efficacy in parents caring for children with diabetes and children leaving neonatal care. ${ }^{15} 16$ Simulation develops skills in professionals but is not yet integrated into TPE. ${ }^{14}$ Whether simulation would extend the benefits of TPE is a matter of debate. Coleman ${ }^{17}$ advocated its use because it was successful in training programmes for health professionals, but Lefèvre et $\mathrm{al}^{18}$ thought Simulation in Therapeutic Patient Education (S-TPE) may be too complicated for patients and could present difficulties for multimorbid, low literacy, or fragile patients.

We thus designed this pilot study to determine if S-TPE was feasible and acceptable to patients and educators and to identify facilitators or barriers to its incorporation into routine TPE practice. We also aimed to ensure that the simulation was accessible to carers carrying out TPE and that the methods and means were accessible to them. This research is essential in order to enable a multi-centre trial to be carried out afterwards to study the effects of this S-TPE on patients.

\section{METHODS}

\section{Study population}

The study population included adults with type 1 or 2 diabetes who needed insulin and diabetes educators in charge of TPE at their institution. The criteria for inclusion were as follows: to be of legal age, to have given their unopposed consent and to be insulin-dependent diabetic who had participated in a full TPE programme (three sessions) for the implementation of a Free Style Libre. The exclusion criteria were as follows: to be subject to a legal protection measure (curatorship, guardianship) or the subject of a legal safeguard measure or to be of legal age and incapable or unable to express consent. Patients, drawn at random from the list of eligible patients and then contacted by telephone, were enrolled between March and June 2019 at Dijon Bourgogne University Hospital. They received the protocol in the mail, and then the educator explained the study over the phone. All participants provided written informed consent before starting the trial. All educators trained in diabetes patient therapeutic education were eligible for the trial and provided informed consent.

\section{Outcomes}

Our two primary outcomes were (1) the patients' and educators' perception of the usefulness of S-TPE and (2) patient satisfaction level at the conclusion of the simulation sequence. Our secondary outcomes were (1) change in patients' S-TPE self-efficacy score (pre to post), (2) patients' anxiety scores and (3) organisational, human, material and temporal facilitating and limiting factors for patients and educators.
To obtain these outcomes, we administered a series of five questionnaires to patients and two to educators. Ahead of the S-TPE session, the following questionnaires were given to patients only, to measure their baseline score:

- Self-efficacy was measured by the self-administered Schwarzer General Self-Efficacy Scale (GSES), ${ }^{19}$ which we adapted to patients who wear a continuous interstitial glucose metre (online supplemental appendix 1).

- Anxiety was measured by the validated French translation of the State and Trait Anxiety Inventory (STAI). ${ }^{20}$ The STAI contains two questionnaires, one measuring the respondent's usual emotional state (trait anxiety questionnaire-STAI-Y1) and one measuring their situational anxiety (state anxiety questionnaire-STAI-Y2). Each questionnaire includes 20 items to be rated on a 4-point Likert scale ('almost never' to 'almost always') (online supplemental appendix 2). The level of a patient's nervousness and anxiety during the S-TPE session was determined by their score on the STAI-Y2 questionnaire. Score thresholds are detailed in online supplemental appendix 2.

At the end of the S-TPE session, the following questionnaires were administered to patients and educators, or patients only:

- The GSES and STAI-Y2 were re-administered to patients only, to obtain post-intervention scores for self-efficacy and situational anxiety.

- A self-administered questionnaire, scored on a 5-point Likert scale from 'strongly disagree' to 'strongly agree', was given to patients and educators, to measure their perception of S-TPE's usefulness. The patients' questionnaire contains four items (online supplemental appendix 3) and the educators' eight items (online supplemental appendix 4).

- Patients completed a self-administered satisfaction questionnaire (online supplemental appendix 5) that contained 12 items, scored on a 5-point Likert scale from 'strongly disagree' to 'strongly agree'. Based on level I ('Evaluation-Reaction') of Kirkpatrick's global model for evaluating training courses,${ }^{21}$ and on criteria for measuring the quality of therapeutic education, ${ }^{7}$ this questionnaire incorporated the following elements: objectives, expectations, progression, questioning, method, place, duration, quality of the exchanges with the participants and professionals, and recommendation to another person.

- A final self-administered questionnaire administered to patients (online supplemental appendix 6) and educators (online supplemental appendix 7) containing three open-ended questions on the organisational, human, material, temporal, facilitating and limiting factors of S-TPE and areas for improvement.

To improve and deepen the transcripts of responses to the three open-ended questions, an investigator (CP) conducted a semi-directed follow-up phone interview 15-30 days after the S-TPE session. 
Box 1 Skills for which simulation brings added value to therapeutic patient education (10 statements)

D1: Simulation is recommended for learning to cope with unusual/ infrequent situations.

- D2: Simulation is recommended for developing communication skills.

- D3: Simulation is recommended for promoting the integration of new technologies in disease self-management.

- D4: Simulation is recommended for promoting partnerships between the care team and the patient for his/her own health or as an expert patient.

- D5: Simulation is recommended for learning to cope with stress.

- D6: Simulation is recommended for reinforcing the feeling of self-efficacy.

- D7: Simulation is recommended for learning how to adjust treatment.

- D8: Simulation is recommended for learning how to manage a crisis or emergency.

- D9: Simulation is recommended to learn to involve the social network in care.

- D10: Simulation is recommended for increasing the motivation to take care of oneself.

\section{Skills covered by the S-TPE session}

We based our trial on S-TPE recommendations made by a group of 25 TPE and simulation experts and expert diabetes patients who came to consensus at a conference in December 2017. ${ }^{22}$ They recommended 10 objectives and specified learner characteristics, conditions of use and ethical conditions (box 1 ).

We set up the pilot to test these objectives: 'use simulation to promote integration of new technologies into self-management of diseases' and 'use simulation to show patients how to manage a crisis or emergency'. The simulation was developed by educators, including two nurses and a doctor in charge of the TPE, the nurse in charge of the diabetology department, a TPE expert and the three people responsible for simulation training at our institution, two of whom were trained in both TPE and simulation. The educators decided to incorporate three more objectives that can be described as 'taking the proper steps when faced with hypoglycaemia': (1) 'identifying possible signs of hypoglycaemia to initiate appropriate management'; (2) 'interpreting the screen data of the continuous interstitial glucose metre' and (3) 'how to act in cases of hypoglycaemia'.

The educators ran through the simulation three times to accustom themselves to pre-briefing and debriefing patients who might have different reactions.

\section{Description of S-TPE}

Standard TPE comprises four sessions where two or three trained physicians or nurses teach up to 10 patients. The educators conducted a single session with each group of patients. One patient simulated and the others observed. Our S-TPE were led by a trained health professional who had been practicing TPE for at least 3 years. At the beginning of the S-TPE session, a research technician administered the three pre-intervention questionnaires to patients.

We held three S-TPE sessions, of seven, nine and eight patients. Patients attended one S-TPE session. In each session, one patient was asked to volunteer to be the 'simulating' patient; they were filmed and broadcasted to the other patients who observed in a nearby room. Simulating patients were pre-briefed on the scenario and played the scene as if they were at home in a standardised room. They simulated hypoglycaemia and acted after an interstitial glucose reading. Post-simulation, all patients debriefed together. We used one simulating patient per group because participants and observers benefit equally. ${ }^{23}$

The S-TPE session had three phases:

1. A nurse led the briefing phase that familiarised patients with material, context, confidentiality, ethics rules, instructions and expectations for the simulation. Educators instructed patients to, above all, be kind to one another and to suspend judgement and guaranteed this behaviour. The simulating patient was also briefed on the scenario and paraphrased it to ensure they understood. The patient was told educators would intervene if they deviated from the scenario, in the form of a visit during the simulation.

2. In the scenario phase (scenario), the simulating patient's performance was guided by the trainer. ${ }^{24}$

3. All educators and patients participated in the steps of the debriefing phase: description, analysis, synthesis (table 1). Then, patients and educators filled out postintervention (section Outcomes). The intervention followed the methodology recommended by the experts in their consensus conference. ${ }^{22}$ TPE sessions always remained focused on the objectives of the session, that is, here the management of hypoglycaemia with an interstitial glucose metre, as well as the recognition of the signs of hypoglycaemia, glycaemic corrective actions and the particularities of continuous interstitial glucose reading. Everything was planned in the guide written for the session so all three groups received the same education. Online supplemental figure 1 shows the process of this research.

\section{Statistical analysis}

Our primary analysis was based on data provided by patients who answered the study questionnaires. We used descriptive statistics to characterise the patients' socio-demographic characteristics and expressed quantitative variables as numbers and percentages. Quantitative variables were reported as means and their SD, with minimum (min) and maximum $(\max )$ value for scores. We used a $\chi^{2}$ test or Fisher exact test to compare qualitative variables pre-intervention and post-intervention. We compared means with a Student t-test for matched pairs or a Wilcoxon signed-rank test after we determined distribution. For all tests, we considered $\mathrm{p}<0.05$ significant. SAS V.9.4 was used for all analyses. 
Table 1 The three-phase methodology for simulation

$\begin{array}{ll}\text { Briefing } & \text { Familiarises patients with the material and the context. Caregivers explain the rules of confidentiality and } \\ \text { deontology and give instructions for the exercise, stating their expectations. The instructor tells participants } \\ \text { that the most important rule is to be kind to one another and not pass judgement. }\end{array}$

In our qualitative analysis, we organised and interpreted the narrative data, both written and transcribed (see paragraph Study population), to identify themes and create reference categories. ${ }^{25}$ One person (CP) condensed the data and coded it to assign keywords. CP extracted in vivo quotes, characterised them with keywords, sorted them into categories and then derived themes from the categories. We then described different dimensions and identified barriers and facilitators of S-TPE to determine which factors would need to be modified or maintained for a large-scale efficacy trial. Our analysis adhered to the Standards for Reporting Qualitative Research (SRQR). ${ }^{26}$

The primary objective of this non-randomised study was to estimate the feasibility and acceptability of S-TPE. The sample of 24 patients was based on the estimate of Hennink et $a l^{27}$ that 16-24 qualitative interviews generally achieve saturation. No formal sample size calculation was performed.

\section{Patient and public involvement}

Patients and/or the public were involved in the consensus conference that paves this work as well as in the construction of the simulation and the design of the study. Information on the publication of this study will be provided to the patients on the website (http://www.chu-dijon.fr) and the social networks of our hospital.

\section{RESULTS}

\section{Patients' description}

In total, 24 patients were included in the study. One patient was wrongly excluded since he was not wearing an interstitial glucose reading device, and thus was quickly excluded (see table 2 for characteristics).

Wearing an interstitial glucose reading device was an inclusion criterion, and a patient was thus quickly excluded because he was not wearing the device. The 23 participants were $63 \pm 15$ years old, with a $29.5 \pm 15$ year history of diabetes. Among them, 18 (78\%) had comorbid conditions: 4 (17\%) had thyroid disorders; 13 $(57 \%)$ had cardiopulmonary disorders; 13 (57\%) had miscellaneous disorders; $10(43 \%)$ had diabetes-related disorders and 5 (21\%) were deemed as more than $70 \%$ disabled according to the definition of the French social security rating.

\section{Result of the main analysis in patients and educators}

Patients found S-TPE to be very useful (mean score 20.6 \pm 3.5 for a maximum of 25) and expressed high satisfaction at the end of the session (mean $51.9 \pm 4.9$ for a maximum of 60) (table 3). Perceived usefulness of S-TPE was also high among educators, whose scores increased after each session $(30.6 \pm 5.8,36 \pm 1.4$ and $37.5 \pm 3.5$ for sessions 1, 2 and 3, for a maximum, respectively; for a maximum of 40) (table 3 ).

Result of secondary analysis in patients and educators Our analysis of post-S-TPE phone interviews with patients identified these characteristics of S-TPE: tables 4 and 5

\begin{tabular}{|c|c|}
\hline Population characteristics & $(n=23)$ \\
\hline Age (years), (mean $\pm S D)$ & $62.8(14.9)$ \\
\hline Duration of illness (years), (mean $\pm S D)$ & $29.5(15)$ \\
\hline Sex-male, $n(\%)$ & $14(60)$ \\
\hline \multicolumn{2}{|l|}{ Level of education, n (\%) } \\
\hline Elementary & $5(22)$ \\
\hline College & $7(30)$ \\
\hline High school & $8(34)$ \\
\hline Post-baccalaureate & $3(14)$ \\
\hline \multicolumn{2}{|l|}{ Concomitant comorbidities, n (\%) } \\
\hline $\begin{array}{l}\text { Diabetes-related (renal vascular, } \\
\text { ophthalmologic) }\end{array}$ & $10(43)$ \\
\hline Thyroid disorders & $4(17)$ \\
\hline \multicolumn{2}{|c|}{$\begin{array}{l}\text { Cardiopulmonary (MI, hypertension, chronic } 13 \text { (57) } \\
\text { bronchitis) }\end{array}$} \\
\hline Other & $13(57)$ \\
\hline Recognised disability $>70 \%, \mathrm{n}(\%)$ & $5(21)$ \\
\hline
\end{tabular}

MI, myocardial infarction. 


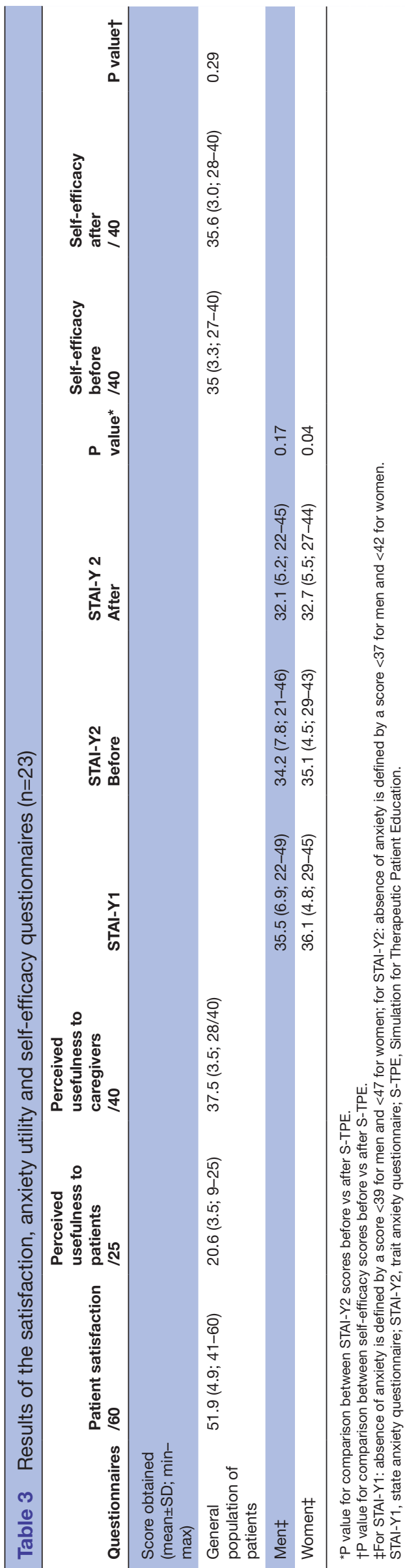

summarise the results for each group and by theme with samples supporting quotes.

All patients expressed their overall satisfaction (23/23), to the point of stating that 'It allowed me to modify my practice'. When asked about technical improvement, they could suggest the following, two patients suggested that the sound should be improved, one of them also stated that he/she did not want the session to last more than 2 hours and the other one reported difficulty in expressing himself/herself in front of the group. When asked about the potential improvements to be made, 19 patients $(82.6 \%)$ did not express a need for changing the technique, one patient suggested doing more different sessions and one expressed he/she would like to review the objectives.

The remaining 21 did not suggest anything to improve.

Benefits of the S-TPE expressed by the patients were as follow: the relationship skills $(7 / 23,30.4 \%)$, 'The exchanges, the relationships with the other participants are richer'; the pedagogical qualities $(15 / 23,65.2 \%)$, 'It's more concrete, it allows you to approach problems in different ways' and the effects on daily life $(8 / 23,34.8 \%)$, 'I've changed, something clicked,' 'I know now'. 'This method removes certain beliefs' (see table 4).

Our analysis of post-S-TPE phone interviews with educators identified these points: 'development of coping skills (not feeling alone, gaining self-confidence, managing stress, talking about one's illness)'; 'a complete overview of the issue (hypoglycaemia in this case) and is used in all its dimensions' and 'concrete, speaking, explicit, it's living for them, they recognised themselves in the situation'. One participant called it 'very positive': 'I would've surrendered at first, but now I'd do it again. It's an immense satisfaction, a lot of fun. I've learned a lot. It was very rewarding to use a new method, to share this' (see table 5).

All (3/3) educators were very satisfied with the method overall. Even though it was considered stressful and requiring skill development, they were willing to try it again. S-TPE improved relational skills for all educators $(3 / 3)$ and two of them stated that this method can be used in patients with physical disabilities or not fluent in French. Two out of three educators also reported the sound quality to be suboptimal. All the educators noted the pedagogical interest of the method and the good quality of the relationship with the group. The exchanges have been improved and enriched, thanks to this method of S-ETP. They report that 'a complicity has appeared, there is a better mutual acquaintance'. The groups should be of a maximum of eight people, because with family carers it can quickly become difficult to manage. All educators noted that S-TPE is relevant with patients, 'Relevant teaching method: it's a fun method that appeals to all the senses: visual, auditory, kinaesthetic. This method allows each person to express themselves, their daily life, they were able to communicate, exchange'. One educator noted that the final synthesis could be improved and that it is necessary to ensure that the objectives are those of the patients. 
Table 4 Analysis of responses to open-ended questions from post-TPE patients $(n=23)$

General perspective on S-TPE

\begin{tabular}{|c|c|c|c|}
\hline Positive considerations $(23 / 23)$ & $\begin{array}{l}\text { Technical Improvements } \\
(2 / 23)\end{array}$ & & \\
\hline $\begin{array}{l}\text { 'It allowed me to modify } \\
\text { my practice', 'I liked the } \\
\text { exchanges', 'I want to do it } \\
\text { again', 'it was interesting'... }\end{array}$ & $\begin{array}{l}\text { 'Work on the hardware and } \\
\text { its technical features' }\end{array}$ & & \\
\hline \multicolumn{4}{|l|}{ Limitations on the use of S-TPE } \\
\hline Positive consideration (21/23) & $\begin{array}{l}\text { Improvement relating to } \\
\text { duration }(1 / 23)\end{array}$ & $\begin{array}{l}\text { Improvement in group } \\
\text { expression (1/23) }\end{array}$ & \\
\hline 'None', 'nothing' & $\begin{array}{l}\text { 'A little long, no more than } 2 \\
\text { hours' }\end{array}$ & $\begin{array}{l}\text { 'Too many people, not easy } \\
\text { to express yourself in front of } \\
\text { others' }\end{array}$ & \\
\hline \multicolumn{4}{|l|}{ Benefits of using S-TPE } \\
\hline Relationship skills (7/23) & Pedagogical qualities (15/23) & Effects on daily life (8/23) & \\
\hline $\begin{array}{l}\text { 'The exchanges, the } \\
\text { relationships with the other } \\
\text { participants are richer' }\end{array}$ & $\begin{array}{l}\text { 'It's more concrete, it allows } \\
\text { you to approach problems in } \\
\text { different ways' }\end{array}$ & $\begin{array}{l}\text { 'I've changed, I've clicked,' } \\
\text { 'I know now. This method } \\
\text { removes certain beliefs' }\end{array}$ & \\
\hline \multicolumn{4}{|c|}{ Suggested improvements to the use of S-TPE } \\
\hline None (19/23) & $\begin{array}{l}\text { Proposal on other topics } \\
(1 / 23)\end{array}$ & Technical improvement (1/23) & $\begin{array}{l}\text { Related to the objectives of the } \\
\text { session }(2 / 23)\end{array}$ \\
\hline 'nothing, it was fine' & $\begin{array}{l}\text { 'Do different sessions either } \\
\text { in a theme day or by varying } \\
\text { situations' }\end{array}$ & 'The sound reasoned a little' & $\begin{array}{l}\text { The groups should be 'better at } \\
\text { the onset of the disease', 'that } \\
\text { the groups should be level' }\end{array}$ \\
\hline
\end{tabular}

S-TPE, Simulation for Therapeutic Patient Education.

Two educators noted that 2 hours was the optimal duration for the session, which should neither be reduced nor be exceeded.

Two training sessions were initially scheduled, but extended to three sessions as per educators' request. In the post S-TPE session phone interviews, educators said that they needed five to eight sessions to become fully comfortable with the method.

S-TPE did not change patients' self-efficacy score (35.6 \pm 3 points pre-S-TPE vs $35.3 \pm 3$ points post-S-TPE, $\mathrm{p}=0.29$ ) (table 3). The STAI-Y1 (anxiety status assessment) scored showed that $13.0 \%(3 / 23)$ of patients (all men) had an anxious personality. The STAI-Y2 (anxiety trait) showed that anxiety scores dropped significantly after S-TPE in women $(35.1 \pm 4.5$ pre-S-TPE vs $32.7 \pm 5.5$ post-S-TPE, $\mathrm{p}=0.04)$, but not in men $(34.2 \pm 7.8$ pre-S-TPE vs $32.1 \pm 5.2$ post-S-TPE, $\mathrm{p}=0.17$ ) (table 3 ).

\section{DISCUSSION AND CONCLUSION}

We identified no barriers to implementing a trial to assess the value of an S-TPE programme for adults with diabetes. Our study suggests that S-TPE may decrease patient anxiety, though this finding was statistically significant only for women. On average, patients ranked S-TPE as very useful (20.6/25), with only one patient scoring its usefulness as low (12.5/20). Patient satisfaction at the end of the S-TPE session was high $(51.9 \pm 4.9 / 60)$.
Patients unanimously approved of the approach and said it created a favourable climate for learning and gave them opportunities to talk about problems in their daily life. They appreciated the structured approach, which allowed everyone to express themselves. They felt that the simulation helped them understand the effects of their diseaserelated behaviours without putting themselves at risk

The overall positive reception of S-TPE is encouraging. The only patient who ranked the usefulness of S-TPE as low appeared to prioritise hyperglycaemia rather than hypoglycaemia management (table 4). S-TPE appears to meet the needs of patients with different backgrounds. Two patients in our study were not native French speakers, one had a hearing impairment and another a walking disability; all found S-TPE helpful.

Interviews with educators revealed their fear and stress in the first session and the desire to perform well. They said that their stress lessened during the sessions and that they are now focusing on managing group dynamics, for example, paying attention to each patient and animating patients rather just transmitting information. Educators asked many questions and said they need five to eight S-TPE sessions before they would feel comfortable implementing the method (table 4).

Our pilot study was limited in the following ways: its small sample size (23 patients) limits our ability to generalise findings to the target population of adult patients 


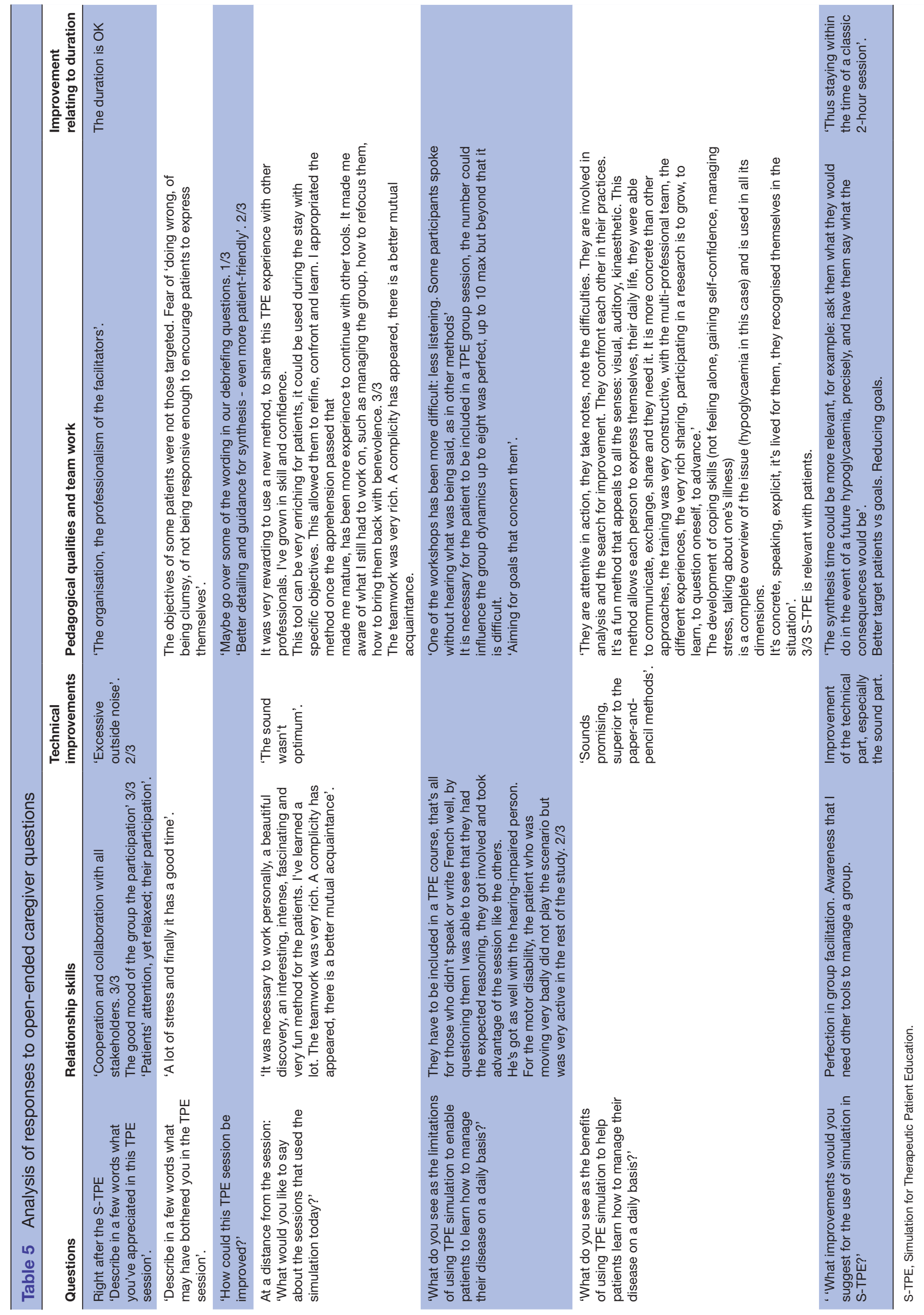


with diabetes. ${ }^{28}$ Like another small pilot study, ${ }^{29}$ we could not show that S-TPE improved self-efficacy in patients.

In contrast to the heterogeneous approaches French health authorities take towards TPE in type 1 and type 2 diabetes, we took a standardised approach to evaluating S-TPE, building on a consensus conference that we recently conducted and published. ${ }^{22}$ These recommendations were to involve 'expert patients' (patients recognised for their advanced understanding of the condition) in constructing the scenarios we used.

Our pilot study demonstrated the acceptability and feasibility of S-TPE for adult patients with diabetes and provided preliminary data that we will use to design and conduct a large randomised controlled trial to evaluate efficacy of S-TPE in diabetes.

Educators said that they 'increased skill and confidence', that 'this tool could be used during the hospital stay with specific objectives' and that 'the pluridisciplinary teamwork in TPE was richer', but studies that include more educators are needed to determine if our positive results are consistent and generalisable. These studies should determine the optimal duration and number of training sessions for educators. If S-TPE works for patients with diabetes, it should be possible to extend the programme to provide S-TPE to patients with other chronic conditions. Expert patients should be systematically involved at an early stage when designing interventions to improve TPE programmes and specifically S-TPE.

This pilot study opens a path to testing the intervention in a larger, more representative population of patients and educators. If the results of our future efficacy trial of S-TPE in patients with diabetes are positive, this method may improve the management of diabetes by patients and educators, by unlocking self-skills previously not accessible, and transform TPE as a patient-centred approach. It will also open the possibility to transpose this method in other chronic diseases.

\section{Author affiliations}

${ }^{1}$ Clinical Investigation Center (INSERM 1432) and Nursing Institute, Bourgogne University Hospital, Dijon, France

${ }^{2}$ INSERM CIC 1432 Clinical Investigation Center, Clinical Epidemiology/Clinical Trials Unit, Bourgogne University Hospital, Dijon, France

${ }^{3}$ Health Education Laboratory, EA-3412, Université Sorbonne Paris Nord - Campus de Bobigny, Paris, France

${ }^{4}$ Department of Endocrinology, Dijon-Bourgogne University Hospital, Dijon, France

${ }^{5}$ Transversal Unit for Therapeutic Patient Education (UTEP), Bourgogne University Hospital, Dijon, France

${ }^{6}$ UFR Sciences Santé, University of Burgundy Franche Comté, Dijon, France

\section{Twitter Marc Bardou @mbardou}

Contributors Each author contributed to the research. CP initiated the project and followed all the steps, ML guided the analysis of the results and the writing of the article. CM and RG followed up on the methodology of the TPE and the recommendations. ND, SR, A-MH, AD and DC made the implementation of the project possible and MB supervised the research methodology and the writing of the article. $\mathrm{CP}$ is the guarantor of this study.

Funding The study was sponsored and funded by Dijon Bourgogne University Hospital.

Competing interests None declared.
Patient consent for publication Not applicable.

Ethics approval This study involves human participants and was approved by Committee for the Protection of Persons Ouest IV, Nantes France, Session n³9/19_3, approved on 7 May 2019, approval n ID : 19-03-22-43920. Participants gave informed consent to participate in the study before taking part.

Provenance and peer review Not commissioned; externally peer reviewed.

Data availability statement Data are available upon reasonable request. Deidentified participant data. Data are available upon reasonable request at the address: CENTRE D'INVESTIGATION CLINIQUE Inserm CIC 1432 Module PlurithématiqueCHU DU DIJON BOURGOGNE 14, RUE GAFFAREL BP 7790821079 DIJON CEDEX FRANCE Maxime.luu@chu-dijon.fr.

Supplemental material This content has been supplied by the author(s). It has not been vetted by BMJ Publishing Group Limited (BMJ) and may not have been peer-reviewed. Any opinions or recommendations discussed are solely those of the author(s) and are not endorsed by BMJ. BMJ disclaims all liability and responsibility arising from any reliance placed on the content. Where the content includes any translated material, BMJ does not warrant the accuracy and reliability of the translations (including but not limited to local regulations, clinical guidelines, terminology, drug names and drug dosages), and is not responsible for any error and/or omissions arising from translation and adaptation or otherwise.

Open access This is an open access article distributed in accordance with the Creative Commons Attribution Non Commercial (CC BY-NC 4.0) license, which permits others to distribute, remix, adapt, build upon this work non-commercially, and license their derivative works on different terms, provided the original work is properly cited, appropriate credit is given, any changes made indicated, and the use is non-commercial. See: http://creativecommons.org/licenses/by-nc/4.0/.

\section{ORCID iDs}

Christelle Pennecot http://orcid.org/0000-0003-4915-6500

Maxime Luu http://orcid.org/0000-0002-9024-293X

Marc Bardou http://orcid.org/0000-0003-0028-1837

\section{REFERENCES}

1 D'Ivernois JF, Gagnayre R. [Learning to educate the patient: pedagogical approach: the Bobigny school]. 3ème. Paris: Maloine, 2011.

2 Lagger E, Pataky Z, Golay A. Efficacité de l'éducation thérapeutique [Effectiveness of therapeutic education]- Revue médicale suisse, 2009. Available: https://www.revmed.ch/RMS/2009/RMS-196/ Efficacite-de-I-education-therapeutique [Accessed 05 Mar 2014].

3 Coppola A, Sasso L, Bagnasco A, et al. The role of patient education in the prevention and management of type 2 diabetes: an overview. Endocrine 2016;53:18-27.

4 Gicquello A. [Is there a place for exercise exploration in asthma?] - Medical Thesis. Univ-Lille 2. Available: https://pepite-depot. univ-lille2.fr/nuxeo/site/esupversions/d37ef6bf-547a-402c-adad5cd9e6d76863 [Accessed cited 2014 Mar 10].

5 Assez N. Characterization of the decision-making skills to be mobilized by cardiovascular patients during a crisis using a delphi method carried out in the Nord Pas de Calais region.]Health public Thesis. Univ-Paris 13: Bobigny, 2012.

6 Faria HTG, Veras VS, Xavier AT da F, et al. Quality of life in patients with diabetes mellitus before and after their participation in an educational program. Revista da Escola de Enfermagem da USP 2013;47:348-54.

7 [Discussion paper. Critical review of the literature]-. Available: https://www.has-sante.fr/portail/upload/docs/application/pdf/200808/document_de_travail._analyse_critique_de_la_litterature.pdf [Accessed 25 Aug 2017].

8 Golay A, Lagger G, Giordan A. How do you motivate the patient to change? Paris: Maloine, 2009.

9 Debussche X, Balcou-Debussche M, Lalouvière LHde V, et al. [Enhancing the access to therapeutic education and reducing health inequalities: Lessons learned from interventions conducted in Africa and Indian Ocean]. Elsevier Masson SAS 2015;9:131-6.

10 Fonte D, Apostolidis T, Lagouanelle-Simeoni M-C. [Psychosocial skills and therapeutic education of patients with type 1 diabetes: a systematic review]. Sante Publique 2014;26:763-77.

11 Deccache A, Berrewaerts J, Libion F. [Training caregivers in therapeutic patient education: what can a programme change?]. Educ Ther Patient/Ther Patient Educ 2009;1:39-48.

12 Marchand C, Iguenane J, David V, et al. Perception of usefulness by patients and carers of an educational evaluation device focused on 
the development of patients' skills: an exploratory study]. Pédagogie Médicale 2010;11:19-35.

13 Lapostolle F, Hamdi N, Barghout M, et al. Diabetes education of patients and their entourage: out-of-hospital national study (educated 2). Acta Diabetol 2017;54:353-60.

14 Chiniara G, Cole G, Brisbin K, et al. Simulation in healthcare: a taxonomy and a conceptual framework for instructional design and media selection. Med Teach 2013;35:e1380-95.

15 Sullivan-Bolyai S, Crawford S, Bova C, et al. PETS-D: impact on diabetes management outcomes. Diabetes Educ 2015;41:537-49.

16 Raines DA. Simulation as part of discharge teaching for parents of infants in the neonatal intensive care unit. MCN Am J Matern Child Nurs 2017;42:95-100.

17 Coleman EA. Extending simulation learning experiences to patients with chronic health conditions. JAMA 2014;311:243-4.

18 Lefèvre T, Gagnayre R, Gignon M. Patients with chronic conditions: simulate to educate? Adv Health Sci Educ Theory Pract 2017;22:1315-9.

19 French Adaptation of the General Self-Efficacy Scale Auto-efficacité Généralisée Michelle Dumont, Ralf Schwarzer \& Matthias Jerusalem, Berlin, Germany,, 2000. Available: http://userpage.fu-berlin.de/\% 7Ehealth/french.htm [Accessed $19 \mathrm{Feb} 2018]$.

20 Gauthier J, Bouchard S. A French-Canadian adaptation of the revised version of Spielberger's State-Trait Anxiety Inventory. Canadian Journal of Behavioural Science 1993;25:559-78.

21 Kirkpatrick JD, Kirkpatrick WK. Kirkpatrick's four levels of training evaluation. Alexandria, VA: ATD Press, 2016.
22 Penneçot C, Gagnayre R, Ammirati C, et al. Consensus recommendations for the use of simulation in therapeutic patient education. Simul Healthc 2020;15:30-8.

23 Semler MW, Keriwala RD, Clune JK, et al. A randomized trial comparing didactics, demonstration, and simulation for teaching teamwork to medical residents. Ann Am Thorac Soc 2015;12:512-9.

24 The guide to good practice in health simulation. Available: http:// www.ch-chambery.fr/upload/docs/application/pdf/2013-05/guide de bonnes_pratiques_en_matiere_de_simulation_en_sante._has dec._2012.pdf [Accessed 26 Apr 2014].

25 Fortin M. Basis and stages of the research process. 2nd edition. Montréal: Chenelière Education, 2010.

26 O'Brien BC, Harris IB, Beckman TJ, et al. Standards for reporting qualitative research: a synthesis of recommendations. Acad Med 2014;89:1245-51.

27 Hennink MM, Kaiser BN, Marconi VC. Code saturation versus meaning saturation: how many interviews are enough? Qual Health Res 2017;27:591-608.

28 [Public Health France, Prevalence and Incidence of Diabetes] Available: https://www.santepubliquefrance.fr/maladies-ettraumatismes/diabete/documents/rapport-synthese/prevalenceet-incidence-du-diabete-et-mortalite-liee-au-diabete-en-france.synthese-epidemiologique [Accessed 27 Nov 2019].

29 Sullivan-Bolyai S, Crawford S, Johnson K, et al. Educating diabetes cAMP counselors with a human patient simulator: a pilot study. $J$ Spec Pediatr Nurs 2012;17:121-8. 